\title{
Secondary Otalgia: Referred Pain Pathways and Pathologies
}

(D) C.D. Norris and (D) N.A. Koontz

\begin{abstract}
SUMMARY: Otalgia is very common, and when the cause of ear pain is not identified on otoscopy and physical examination, cross-sectional imaging is routinely used to evaluate for potential sources of referred ear pain (secondary otalgia). Innervation of the ear structures is complex, involving multiple upper cervical, lower cranial, and peripheral nerves, which transit and innervate a large anatomic territory involving the brain, spine, skull base, aerodigestive tract, salivary glands, paranasal sinuses, face, orbits, deep spaces of the neck, skin, and viscera. Interpreting radiologists must be familiar with these neural pathways and potential sources of secondary otalgia. The purposes of this review are to detail the currently proposed mechanisms of referred ear pain, review the salient neuroanatomy of the complex pathways responsible for secondary otalgia, highlight important benign and malignant etiologies of referred ear pain, and provide a structured search pattern for approaching these challenging cases on cross-sectional imaging.
\end{abstract}

ABBREVIATION: $\mathrm{CN}=$ cranial nerve; $\mathrm{TMJ}=$ temporomandibular joint

O talgia is common and indiscriminate, affecting persons of all ages with nearly a $100 \%$ lifetime prevalence. ${ }^{1,2}$ Frequently, the cause of otalgia can be identified with otoscopy, and when the pathoetiology localizes to the affected ear, it is referred to as a primary otalgia. Common causes of primary otalgia include otitis media, external otitis, folliculitis, cerumen impaction, mastoiditis, myringitis, and neoplasm. ${ }^{3}$ Primary otalgia is far more common in children than in adults. ${ }^{1,4}$ When the pain generator cannot be localized to the affected ear on physical examination and otoscopy, it is referred to as secondary otalgia. Although most secondary otalgia is caused by biomechanical issues of the neck, cervical spine, and temporomandibular joints (TMJs), ${ }^{5}$ one must be vigilant to exclude more ominous causes, such as occult malignancy. Because of the complex innervation of head and neck structures,

Received April 28, 2020; accepted after revision July 18.

From the Department of Radiology and Imaging Sciences, Indiana University School of Medicine, Indianapolis, Indiana.

Levels of contribution: Dr. Norris (first author) and Dr. Koontz (senior author).

Previously presented as an electronic education exhibit at: Annual Meeting of the American Society of Head \& Neck Radiology (ASHNR) 2018, September 26-30, 2018, The Westin Savannah Harbor Golf Resort \& Spa, Savannah, Georgia.

Retrospective review of PACS and RIS at our institution for the purposes of this manuscript was performed in a HIPAA-compliant manner and with review and approval of the IRB at our institution (Indiana University IRB\#1604478948A001).

Please address correspondence to Nicholas A. Koontz, MD, 550 N. University Blvd, Room 0663, Indianapolis, IN 46202; e-mail: nakoontz@iupui.edu;

@nakoontz; @CarrieDNorrisMD

- Indicates open access to non-subscribers at www.ajnr.org

http://dx.doi.org/10.3174/ajnr.A6808 which may yield referred pain from sources outside the ear, it is imperative that a complete history and comprehensive physical examination be performed on patients with otalgia.

When the cause of otalgia is not identified after an appropriate history and physical examination, cross-sectional imaging becomes the primary tool of investigation. Temporal bone CT is the first-line technique for assessing causes within the ear and temporal bone. Assessment of the pharynx, larynx, and other neck sites is typically best accomplished with contrast-enhanced CT of the neck, although MR imaging plays a complementary role and may be superior to CT for some entities. Severity of otalgia rarely correlates with the significance of the pathology. Thus, performing imaging should be based on the patient's history, presence of other symptoms, or other concerning physical examination findings rather than the severity of pain., ${ }^{4,6}$

Because of the complex interplay of multiple upper cervical, lower cranial, and peripheral nerves providing sensory information to and from the ear, localizing the source of referred ear pain is challenging. This complexity is magnified by the diverse anatomic territory transited and innervated by these nerves, which spans portions of the brain, spine, skull base, aerodigestive tract, salivary glands, paranasal sinuses, face, orbits, deep spaces of the neck, skin, and viscera. These cases require a thorough and thoughtful search pattern, scrutinizing the course of potential culprit neural pathways from origin nuclei to end organs.

In this review, which serves as a current update to the classic AJNR review article "The Radiology of Referred Otalgia" by Chen et $\mathrm{al}^{8}{ }^{8}$ we detail the currently proposed mechanisms of referred ear 

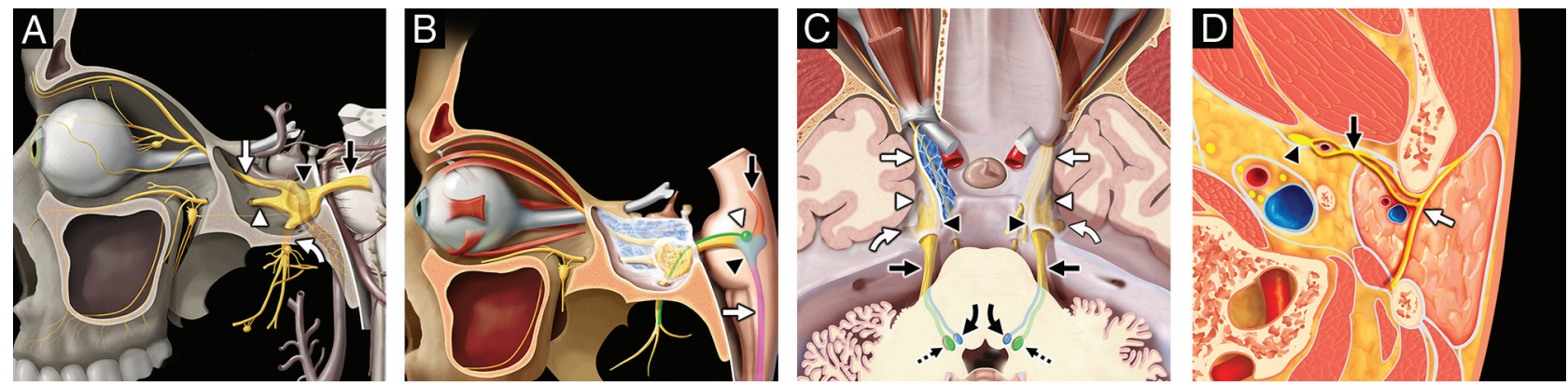

FIG 1. Trigeminal nerve, associated nuclei, and major branches. Sagittal graphic (A) shows the major branches of the trigeminal nerve (CN V), including the preganglionic or cisternal segment (black straight arrow), trigeminal ganglion (black arrowhead) in the trigeminal cave, ophthalmic division (white straight arrow, CN V1) entering the orbit via the superior orbital fissure, maxillary division (white arrowhead, CN V2) exiting at the foramen rotundum, and mandibular division (white curved arrow, CN V3) exiting the skull base at the foramen ovale before transiting the infrazygomatic masticator space. Sagittal graphic $(B)$ highlights the brain stem nuclei of the trigeminal nerve, including the mesencephalic nucleus (orange shading, black straight arrow), main sensory nucleus (blue shading, black arrowhead), spinal nucleus (pink shading, white straight arrow), and motor nucleus (green shading, white arrowhead). Axial graphic (C) demonstrates the course of the trigeminal nerves, including the preganglionic segments (black straight arrows), trigeminal ganglia (black arrowheads), ophthalmic divisions (white straight arrows, CN V1), maxillary divisions (white arrowheads, CN V2), and mandibular divisions (white curved arrows, CN V3), as well as the sensory (blue shading, black curved arrows) and motor (green shading, black dashed arrows) nuclei. Axial graphic (D) shows the relationship of the auriculotemporal nerve (black straight arrow), a complex branch of the mandibular nerve (black arrowhead, CN V3) that transits the infrazygomatic masticator space and parotid space, serving as an extracranial "bridge" linking CN V3 and the intraparotid facial nerve (white straight arrow, CN VII). Graphics are reproduced with permission from Imaging Anatomy: Brain and Spine and Specialty Imaging: Head and Neck Cancer. Copyright Elsevier.

pain, review the salient neuroanatomy, report important benign and malignant etiologies of secondary otalgia, and provide a structured search pattern for approaching secondary otalgia on crosssectional imaging.

\section{MECHANISMS OF REFERRED PAIN}

Pain may be elicited from heat, chemical, and mechanical stimuli, which are perceived by primary afferent nociceptors in the skin, muscles, and viscera in a process known as transduction. ${ }^{9}$ This nociceptive pseudounipolar neuron typically has its cell body in the dorsal root ganglion (or respective sensory ganglion for select cranial nerves [CNs]), 1 axonal branch in the peripheral tissues, and 1 axonal branch in the dorsal horn of the spinal cord or medulla (if the primary afferent is in the head). ${ }^{10,11}$ In a process known as transmission, the primary afferent nociceptors release neurotransmitters to activate second-order neurons, which may decussate immediately and travel via the anterolateral spinal cord (spinothalamic and spinoreticular tracts) or travel along the dorsal cord and decussate in the medulla (medial lemniscus tract). ${ }^{9,12}$ In the head and neck, the primary nociceptive neuron has its cell body in a nucleus of a $\mathrm{CN}$ and ascends via a specific neural pathway (eg, trigeminothalamic tract). ${ }^{13}$ With both somatic and CNs, the second-order neurons terminate on different parts of the thalami, and from there third-order neurons transmit to different locations of the brain cortex (projection). ${ }^{9,12,13}$ Throughout the peripheral and central nervous systems, complex and dynamic excitatory and inhibitory pathways alter the nociceptive signal in a process known as modulation ${ }^{12}$ before the painful stimulus reaches the cortex and is appreciated (perception). ${ }^{11}$

The mechanisms of referred otalgia are incompletely understood and challenging to study because pain is subjective and difficult to measure scientifically. For example, there can be subjective pain without activity in primary afferent nociceptors, and there can be activity in primary afferent nociceptors without subjective pain. ${ }^{9}$ Furthermore, afferents innervating deep structures are difficult to localize and can be misperceived as arising from a site distant from the actual site of stimulation. The elusive phenomenon of referred pain has been widely theorized, and several underlying mechanisms are hypothesized. Some postulate that a single nociceptor may synapse on multiple second-order neurons, and under normal conditions, most of the second-order neurons are latent, and the nociceptive information is not transmitted. ${ }^{14}$ However, with prolonged or intense nociceptive stimulation, previously latent secondorder neurons become activated, and information from regions unrelated to the source of the noxious peripheral stimulus may be conveyed to higher centers of the brain. ${ }^{9,14}$ Others postulate that sympathetic nerves may cause referred pain by sensitizing nociceptors or restricting blood flow in the region of referred pain. ${ }^{15}$ One theory widely considered as a cause of hyperallodynia, the central sensitization theory, may also play a role in referred pain. This theory asserts that through a series of complex molecular interactions and neuroplasticity, previously subthreshold synaptic inputs are recruited and stimulated to generate an action potential output, which allows "hyperexcitable" neurons to send nociceptive information to the brain, even if they innervate areas not directly stimulated. ${ }^{16-20}$ Last, the theory of convergence postulates that a single second-order neuron may receive nociceptive input from multiple primary somatic or visceral afferents from separate sites (eg, the heart and the muscles of the left shoulder), but the brain cannot accurately decipher which site the stimulus originated from, thus it misinterprets and incorrectly localizes the sensation..$^{20-23}$

\section{NEUROANATOMY OF SECONDARY OTALGIA}

Afferent innervation of the ear is complex and involves multiple cranial and somatic nerves. There is considerable overlap and ambiguity within the nervous supply both within the ear and the related areas of innervation in the head and neck, which includes contributions from cervical nerves (C II and C III), CN V (Fig 1), 

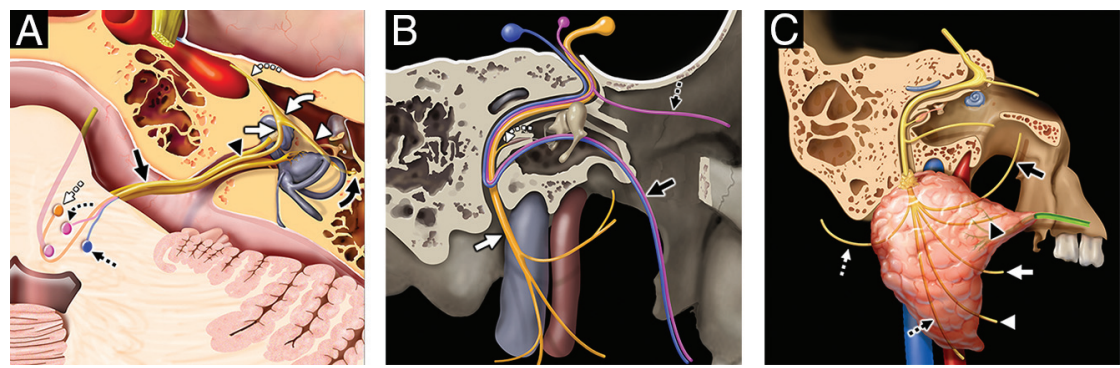

FIG 2. Facial nerve, associated nuclei, and major branches. Axial graphic $(A)$ shows the segments of the facial nerve (CN VII), including the cisternal (black solid arrow), canalicular (black arrowhead), labyrinthine (white solid arrow), tympanic (white arrowhead), and proximal descending mastoid (black solid curved arrow) segments. Note additionally the geniculate ganglion (white solid curved arrow) and greater superficial petrosal nerve (white dashed curved arrow). The 3 brain stem nuclei of CN VII are seen at the level of the pons, including the motor (orange shading, white dashed straight arrow), superior salivatory (pink shading, black dashed curved arrow), and solitary tract nuclei (blue shading, black dashed straight arrow). Sagittal graphic (B) shows the motor, sensory, and parasympathetic fibers of the facial nerve and its major branches. Motor fibers (orange shading) give off the small stapedius motor nerve (white dashed curved arrow) before exiting the skull base at the stylomastoid foramen as the extracranial CN VII (white solid arrow), which is purely motor. Parasympathetic fibers (shaded pink) give off the greater superficial petrosal nerve (black dashed straight arrow) that innervates the lacrimal gland and contribute to the chorda tympani nerve (black solid arrow). The chorda tympani nerve also receives special sensory fibers, providing taste to the anterior two-thirds of the tongue in addition to providing parasympathetic innervation of the submandibular and sublingual glands. Sagittal graphic $(C)$ shows the extracranial motor branches of CN VII, including the temporal (black solid arrow), zygomatic (black arrowhead), buccal (white solid arrow), mandibular (white arrowhead), cervical (black dashed straight arrow), and posterior auricular (white dashed straight arrow) branches. Graphics are reproduced with permission from Imaging Anatomy: Brain and Spine. Copyright Elsevier.

CN VII (Fig 2), CN IX (Fig 3), and CN X (Fig 4). ${ }^{6-8}$ To thoroughly evaluate a patient with otalgia, one must be familiar with the sensory innervation of the ear, as well as the shared neural pathways outside the ear that may contribute to referred ear pain (Table 1).

\section{Cervical Nerves (C II and C III)}

The great auricular and lesser occipital nerves serve as the major cervical nerve origins for sensory innervation of the ear. Both the great auricular and lesser occipital nerves are derived from the cervical plexus of C II and C III. Together these nerves innervate most of the inferomedial and lateral surfaces of the pinna, ear lobule, skin in front of and behind the external ear, and angle of the mandible. ${ }^{24}$ The great auricular nerve courses behind the sternocleidomastoid before ascending along its superficial surface just deep to the platysma to the level of the parotid gland, where it bifurcates into an anterior branch, innervating skin of the preauricular face overlying the parotid gland, and a posterior branch, innervating the postauricular skin overlying the mastoid process, as well as the skin of the posterior external ear. The lesser occipital nerve ascends from the cervical plexus along the posterior margin of the sternocleidomastoid, eventually innervating the postauricular skin and scalp.

Primary otogenic pathologies may stimulate pain along the course of these cervical nerve branches, including folliculitis, chondritis, neoplasm, and cellulitis. ${ }^{3}$ In the absence of otogenic pathology, other structures receiving afferent innervation of cervical nerves C2 and C3 may cause referred pain through sensory "crosstalk." 25 These structures include the nerve roots, facet joints, overlying skin, and muscles of the ipsilateral anterior, lateral, and posterior neck. ${ }^{26-28}$ Therefore, when imaging a patient with unexplained otalgia, it is critical to scrutinize the upper spine, including the spinal canal, neural foramina, facet joints (Fig 5), and surrounding soft tissues, as well as along the expected courses of the great auricular and lesser occipital nerves (Fig 6) as potential sites of pathology that may serve as a pain generator.

\section{Cranial Nerve $\boldsymbol{V}$}

One of the most common neural pathways involved with both primary and secondary otalgia is via the trigeminal nerve $(\mathrm{CN} \mathrm{V}){ }^{2,29,30} \mathrm{CN} \mathrm{V}$ is a mixed nerve, containing both motor efferents and sensory afferents with 4 origin nuclei (motor, main sensory, mesencephalic, and spinal) whose locations span the midbrain, pons, medulla, and upper cervical cord ${ }^{31}$ (Fig 1). The trigeminal nerve exits the brain stem along the lateral pons near its junction with the brachium pontis, transits the prepontine cistern (cisternal or preganglionic segment), and enters the trigeminal cistern (Meckel cave), forming the trigeminal ganglion. The postganglionic $\mathrm{CN}$ V trifurcates into CN V1 (ophthalmic nerve), CN V2 (maxillary nerve), and CN V3 (mandibular nerve) branches with CN V1 and $\mathrm{CN}$ V2, continuing anteriorly through the cavernous sinus and $\mathrm{CN}$ V3 immediately exiting the skull base via the foramen ovale. Distal to the cavernous sinus, CN V1 exits the skull via the superior orbital fissure and its branches supply sensory innervation to orbits, face, scalp, nasal structures, sphenoid sinus mucosa, and posterior ethmoid sinus mucosa. After transiting the cavernous sinus, CN V2 exits the skull via the foramen rotundum, transits the pterygopalatine fossa, travels along the floor of the orbit via the infraorbital nerve canal, and then exits the orbit at the infraorbital foramen providing sensory innervation to the cheek, maxillary teeth, and maxillary sinus mucosa. Small sensory branches of CN V2 also transit the pterygopalatine fossa, including those contributing to the greater palatine nerve (a mixed nerve supplying the posterior hard palate and posterior maxillary gingiva), lesser palatine nerve (a mixed nerve supplying portions of the soft palate and tonsil), and nasopalatine nerve (a mixed nerve supplying the anterior hard palate, anterior maxillary teeth, and nasal septum). After the mandibular branch (CN V3) exits the cranial cavity through the foramen ovale, it passes through the infrazygomatic masticator space between the tensor veli palatini and the lateral pterygoid, and it begins giving off muscular (motor to the muscles of mastication, tensor veli palatini, and tensor tympani) and sensory branches.

The trigeminal nerve supplies the anterosuperior pinna and external auditory canal, as well as the lateral aspect of the tympanic membrane via the auriculotemporal nerve (Fig 1), a major branch of $\mathrm{CN} \mathrm{V} 3$ that also provides secretomotor innervation to 

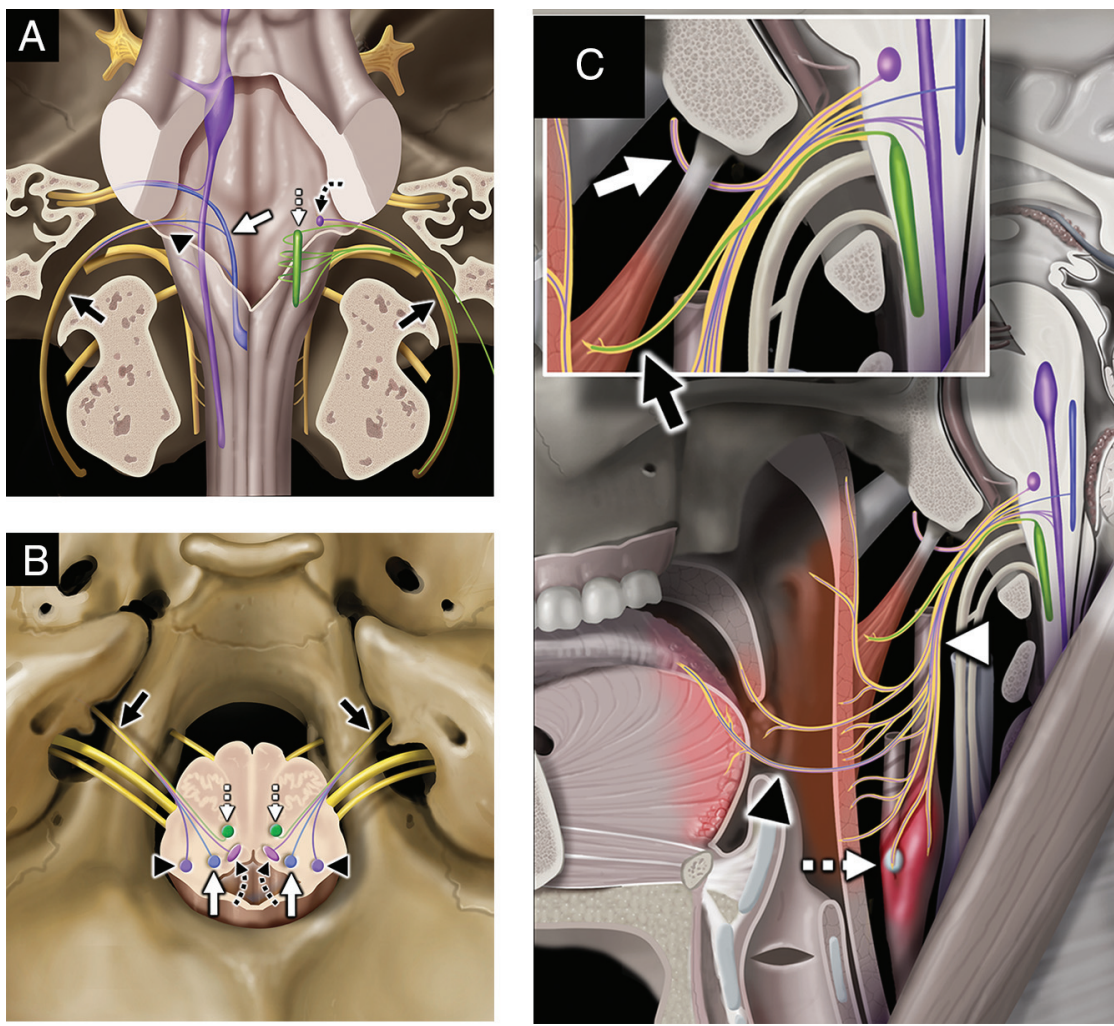

FIG 3. Glossopharyngeal nerve, associated nuclei, and major branches. Coronal graphic $(A)$ shows the glossopharyngeal nerves (black solid arrows, CN IX) exiting the skull base at the jugular foramina. CN IX is a mixed nerve, including afferent sensory fibers to the spinal nucleus of $C N V$ (purple shading, black arrowhead), afferent special sensory fibers (taste from posterior twothirds of the tongue) to the solitary tract nucleus (blue shading, white solid arrow), efferent motor fibers from the nucleus ambiguus (green shading, white dashed straight arrow), and efferent parasympathetic fibers from the inferior salivatory nucleus (lavender shading, black dashed curved arrow). Axial graphic (B) shows CN IX (black solid arrows) departing the medulla laterally at the postolivary sulcus and exiting the skull base at the pars nervosa segment of the jugular foramina. Note the brain stem nuclei of CN IX, including the spinal nucleus of $\mathrm{CN} V$ (purple shading, black arrowheads), solitary tract nucleus (blue shading, white solid arrows), inferior salivatory nucleus (pink shading, black dashed curved arrows), and nucleus ambiguus (green shading, white dashed straight arrows). Sagittal graphic (C) demonstrates the complex extracranial innervation provided by $\mathrm{CN}$ IX, including motor innervation of the stylopharyngeus muscle (black solid arrow, magnified inset), sensory innervation from the middle ear and parasympathetic innervation to the parotid gland via the tympanic (Jacobson) nerve (white solid arrow, magnified inset), sensory and taste from the posterior two-thirds of the tongue (black arrowhead), sensory from the soft palate and oropharynx (white arrowhead), and viscerosensory to the carotid sinus and body (white dashed straight arrow). Graphics are reproduced with permission from Imaging Anatomy: Brain and Spine. Copyright Elsevier.

the parotid gland. ${ }^{32}$ The auriculotemporal nerve acts as an extracranial bridge linking the facial (CN VII) and trigeminal (CN V3) nerves, thus may serve as a conduit for perineural tumor spread between CN VII and CN V ${ }^{33}$ (Fig 7). Other important branches of $\mathrm{CN} \mathrm{V} 3$ with regard to secondary otalgia include the lingual, buccal, and inferior alveolar nerves, which together provide sensory innervation to the oral cavity, gingival and buccal mucosa, palate, floor of the mouth, anterior two-thirds of the tongue (general sensory; not gustatory, which is supplied by the chorda tympani branch of $\mathrm{CN}$ VII), mandibular teeth, and mandible, including the TMJ. ${ }^{32}$
Primary pathologies that may stimulate $\mathrm{CN}$ V3 overlap those that affect the aforementioned C II and C III cervical nerves, specifically including pathologies affecting the external auditory canal, such as otitis externa, foreign body, cerumen impaction, keratosis obturans, and squamous cell carcinoma. ${ }^{3}$ However, any pathology involving the anatomic distribution of $\mathrm{CN}$ V3 may cause ear pain through sensory "cross-talk" 25 ; therefore, one must scrutinize the full course of $\mathrm{CN} \mathrm{V} 3$ and its branches from origin nuclei to end organs for pathology when assessing patients with secondary otalgia. Common culprits include TMJ dysfunction (Fig 8); sialolithiasis (Fig 9), sialadenitis, sialodochitis, and other sublingual, submandibular, and parotid infections; salivary gland neoplasms (Fig 7); oral cavity neoplasm; and odontogenic infection ${ }^{32,34-37}$ (Fig 10).

\section{Cranial Nerve VII}

The facial nerve (CN VII) is a mixed nerve that transmits motor fibers to the muscles of facial expression, special sensory (taste) to the anterior two-thirds of the tongue, and parasympathetic innervation to the submandibular, sublingual, and lacrimal glands. ${ }^{38}$ Accordingly, it has 3 distinct brain stem nuclei (motor, solitary tract, and superior salivatory nuclei for motor, taste, and salivation or lacrimation, respectively) located in the pons (Fig 2). After exiting the lateral pontomedullary junction, distinct motor and sensory roots of CN VII merge together and transit the cerebellopontine angle cistern (cisternal segment of CN VII), course through the internal auditory canal anterosuperiorly, and then travel through the labyrinthine segment of the facial nerve canal to the level of the geniculate ganglion. At the geniculate ganglion, the greater superficial petrosal nerve branches from CN VII and courses anteromedially, and CN VII proper turns posterolateral and descends through the temporal bone via tympanic and descending mastoid segments before exiting the base of the temporal bone into the parotid space at the stylomastoid foramen.

Branches of CN VII function to directly innervate parts of the ear, including the posterior auricular nerve (Fig 2), which joins with branches of CN IX and CN X to provide sensory information from the conchal bowl, external ear canal, and tympanic membrane. $^{32}$ The posterior auricular nerve originates from the proximal extracranial facial nerve, just below the stylomastoid foramen, 

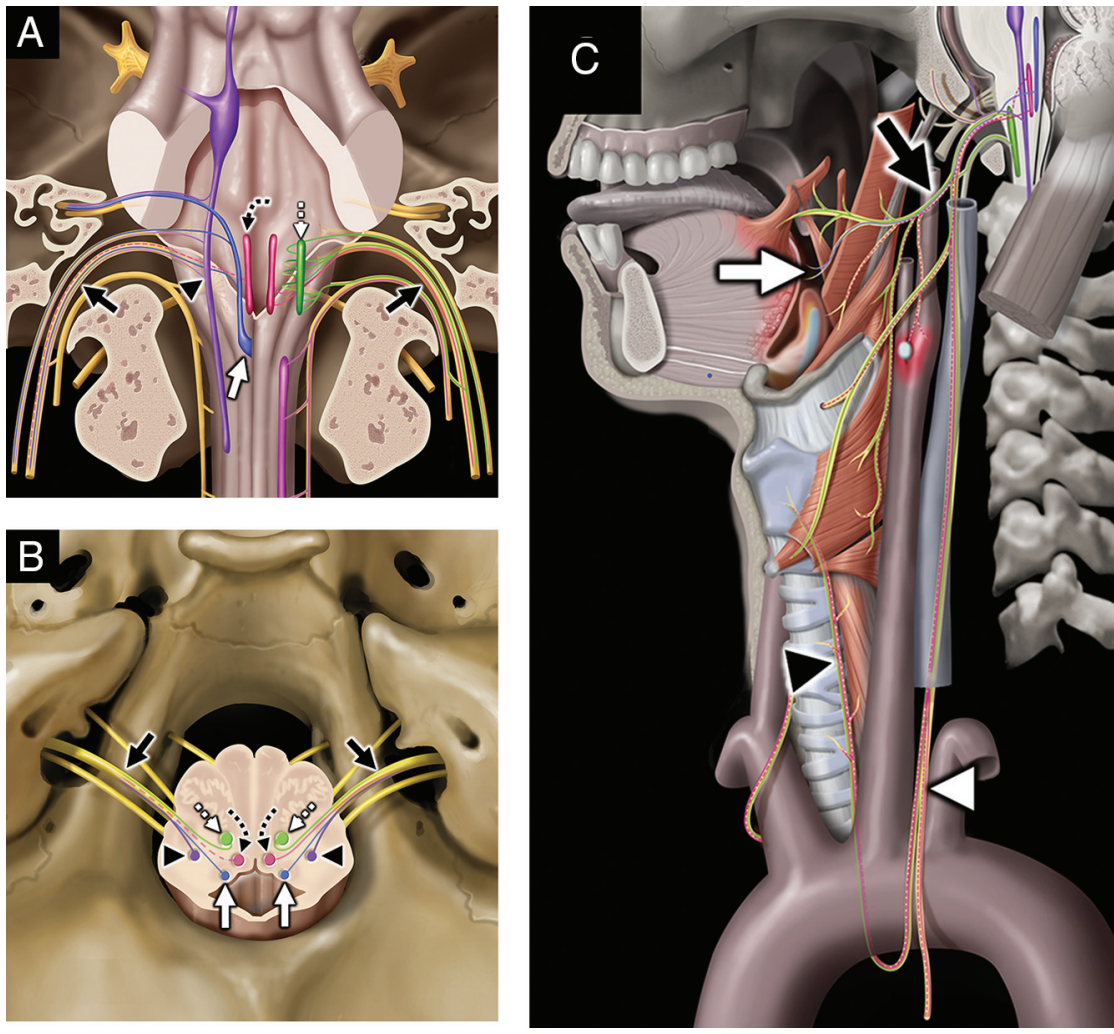

FIG 4. Vagus nerve, associated nuclei, and major branches. Coronal graphic $(A)$ shows the vagus nerves (black solid arrows, CN X) exiting the skull base at the jugular foramina. CN X is a mixed nerve, including afferent sensory fibers to the spinal nucleus of $\mathrm{CN} \vee$ (purple shading, black arrowhead), afferent special sensory fibers (taste from epiglottis and valleculae) to the solitary tract nucleus (blue shading, white solid arrow), efferent motor fibers from the nucleus ambiguus (green shading, white dashed straight arrow), and both efferent parasympathetic fibers from and afferent viscerosensory fibers to the dorsal vagal nucleus (rose shading, black dashed curved arrow). Axial graphic (B) shows CN X (black solid arrows) departing the medulla laterally at the postolivary sulcus and exiting the skull base at the pars vascularis segment of the jugular foramina. Note the brain stem nuclei of $\mathrm{CN} \mathrm{X}$, including the spinal nucleus of $\mathrm{CN} V$ (purple shading, black arrowheads), solitary tract nucleus (blue shading, white solid arrows), dorsal vagal nuclei (rose shading, black dashed curved arrows), and nucleus ambiguus (green shading, white dashed straight arrows). Sagittal graphic (C) demonstrates the complex extracranial innervation provided by $\mathrm{CN} \mathrm{X}$, including motor innervation of the soft palate and constrictors via the pharyngeal plexus (black solid arrow); motor innervation of the muscles of the larynx (except cricothyroid) via the recurrent laryngeal nerve (black arrowhead); special sensory (taste) from the epiglottis and valleculae (white solid arrow); afferent sensory from the external ear and skull base; parasympathetic innervation of the cervical, thoracic, and abdominal viscera; and viscerosensory afferents (white arrowhead) from the larynx, visceral space, chest, and abdomen. Graphics are reproduced with permission from Imaging Anatomy: Brain and Spine. Copyright Elsevier.

ganglion can involve additional segments of the facial nerve, resulting in facial palsy, hearing loss, and ear pain, as well as vesicular rash in zoster oticus. ${ }^{39}$ The nerve of the pterygoid canal (Vidian nerve) and greater superficial petrosal nerve provide parasympathetic innervation to the nasal mucosa, sphenoid and ethmoid sinuses, portions of the palate, and lacrimal glands, which can also be a source referred otalgia in the setting of mucosal inflammation, sinusitis (Fig 11), large nasal septal bone spurs, or dacryoadenitis. ${ }^{8,40}$

\section{Cranial Nerve IX}

The glossopharyngeal nerve (CN IX) is a mixed nerve with motor, general sensory, special sensory (taste), viscerosensory, and parasympathetic innervation. ${ }^{41}$ CN IX has 4 discrete brain stem nuclei, all of which are in part located in or extend through the medulla, including the nucleus ambiguus (motor), spinal nucleus of CN V (sensory), solitary tract nucleus (taste), and inferior salivatory nucleus (parasympathetic) (Fig 3). CN IX departs the medulla laterally at the postolivary sulcus, courses anterolaterally through the basal cistern along with $\mathrm{CN}$ $\mathrm{X}$ and the accessory nerve (CN XI), exits the skull base via the pars nervosa portion of the jugular foramen, and descends within the carotid space lateral to the internal carotid artery at the level of the nasopharynx before providing its constituent branches.

In addition to contributing to direct sensory innervation of the inner surface of the tympanic membrane and the middle ear through sensory fibers of the tympanic nerve (Jacobson nerve, Fig 3), CN IX also provides mixed sensory, motor, parasympathetic, and viscerosensory innervation to portions of the

where it ascends ventral to the mastoid tip before communicating with branches of the great auricular and lesser occipital nerves (see "Cervical Nerves") to innervate the ear. The complex anatomic relationships between cranial and cervical nerve branches serve as a substrate for "cross-talk" and propagation of referred pain from pathology along the course of any of these nerves.

Other portions of the facial nerve complex that can contribute to referred otalgia include the geniculate ganglion, which relays a complex array of general sensory, special sensory (taste, via chorda tympani fibers), parasympathetic, and motor fibers; the greater superficial petrosal nerve; and the nerve of the pterygoid canal (Vidian nerve). Herpes virus reactivation from the geniculate head and neck, including innervation of the stylopharyngeus muscle, posterior third of the tongue, palatine tonsils, carotid body and sinus, pharyngeal mucosa, parapharyngeal space, and retropharyngeal space. ${ }^{32}$

Causes of secondary otalgia may originate anywhere along the geographically extensive pathway of the glossopharyngeal nerve, necessitating thorough imaging review of the expected course of CN IX and its branches from origin nuclei to end organs. Perhaps the most ominous cause of secondary otalgia is malignancy, particularly squamous cell carcinoma, which may trigger referred pain via CN IX through its involvement of the pharyngeal mucosal space (Figs 6 and 12). Additionally, CN IX afferents may further be 
Table 1: Sensory innervation of the ear and potential referred pain origin sites

\begin{tabular}{|c|c|c|}
\hline Nerve & Primary Ear Sensory Innervation & Origin Site of Referred Pain \\
\hline $\mathrm{CN}$ II and CN III & $\begin{array}{l}\text { Inferomedial and lateral pinna } \\
\text { Pre- and postauricular skin } \\
\text { Lobule }\end{array}$ & $\begin{array}{l}\text { Skin overlying angle of mandible } \\
\text { Lateral neck } \\
\text { Muscles of neck } \\
\text { Upper cervical facet joints and nerve roots } \\
\text { Atlantoaxial joint }\end{array}$ \\
\hline CN V & $\begin{array}{l}\text { Anterosuperior pinna } \\
\text { External auditory canal } \\
\text { Tympanic membrane }\end{array}$ & $\begin{array}{l}\text { Gingival and buccal mucosa of oral cavity } \\
\text { Palate } \\
\text { Floor of the mouth } \\
\text { Anterior two-thirds of the tongue (sensory nerves) } \\
\text { Mandibular teeth } \\
\text { TMJ } \\
\text { Mandible } \\
\text { Nasal mucosa (sensory nerves) } \\
\text { Paranasal sinus mucosa (sensory nerves) } \\
\text { Parotid gland }\end{array}$ \\
\hline CN VII & $\begin{array}{l}\text { Conchal bowl } \\
\text { External auditory canal } \\
\text { Tympanic membrane }\end{array}$ & $\begin{array}{l}\text { Nasal mucosa (parasympathetic nerves) } \\
\text { Sphenoid and ethmoid sinuses (parasympathetic nerves) } \\
\text { Anterior two-thirds of the tongue (taste fibers) }\end{array}$ \\
\hline CNIX & Tympanic membrane & $\begin{array}{l}\text { Stylopharyngeus muscle } \\
\text { Posterior third of the tongue } \\
\text { Palatine tonsil } \\
\text { Carotid body } \\
\text { Pharyngeal mucosa } \\
\text { Parapharyngeal space } \\
\text { Retropharyngeal space }\end{array}$ \\
\hline $\mathrm{CNX}$ & $\begin{array}{l}\text { Concha } \\
\text { Postauricular skin } \\
\text { Posterior external auditory canal } \\
\text { Tympanic membrane }\end{array}$ & $\begin{array}{l}\text { Oropharynx (vallecula and constrictor muscles) } \\
\text { Larynx } \\
\text { Hypopharynx (pyriform sinus) } \\
\text { Visceral space (thyroid, esophagus, and trachea) }\end{array}$ \\
\hline
\end{tabular}

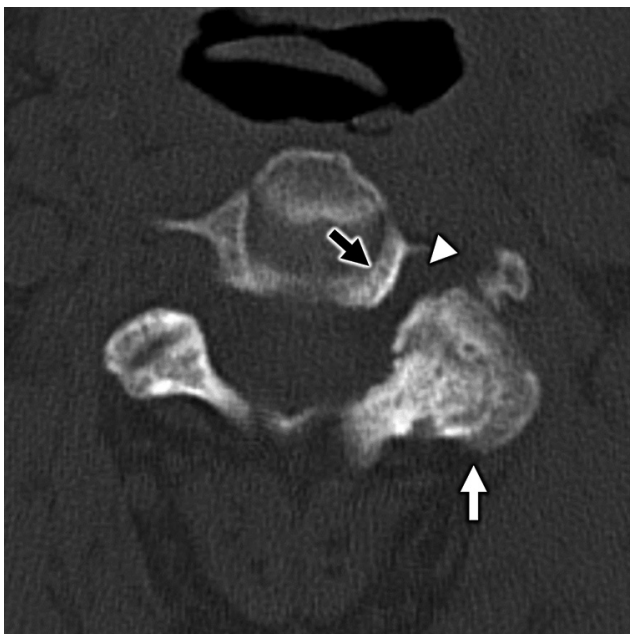

FIG 5. A 55-year-old man with secondary otalgia due to cervical spondylosis. Axial bone algorithm CT shows marked left-sided facet arthropathy (white arrow), which along with uncovertebral hypertrophy (black arrow) results in narrowing of the C II to C III neural foramen (white arrowhead). Impingement of the C III nerve root can lead to otalgia via referred pain along the great auricular or lesser occipital nerves.

stimulated via metastatic lymphadenopathy encroaching on the retropharyngeal or carotid spaces ${ }^{2,32,42}$ (Figs 6 and 12).

Benign processes can also cause secondary ear pain through stimulation of CN IX afferents, including nonsuppurative tonsillitis, tonsillar or peritonsillar abscess, suppurative retropharyngeal

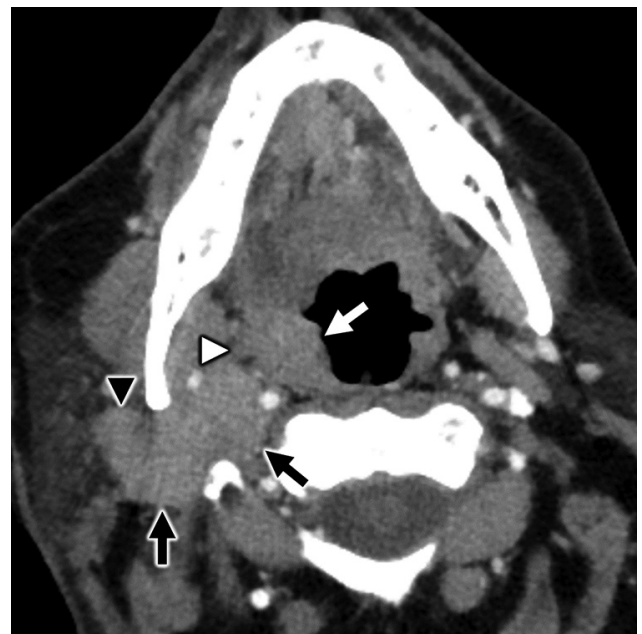

FIG 6. A 64-year-old man with secondary otalgia caused by palatine tonsil squamous cell carcinoma. Axial contrast-enhanced CT shows a right palatine tonsil mass (white arrow) with deep invasion through the superior constrictor (white arrowhead) into the parapharyngeal space. Conglomerate right level II cervical adenopathy (black arrows) with extracapsular spread displaces the carotid space and invades the parotid tail (black arrowhead). In this case, the patient's referred otalgia may be caused by involvement of CN IX, CN X, and/or upper cervical nerve branches (great auricular or lesser occipital).

adenopathy, transient perivascular inflammation of the carotid syndrome (Fig 13), and stylohyoid (Eagle) syndrome. ${ }^{17,43-46}$ Additionally, patients with neurovascular compression of the 


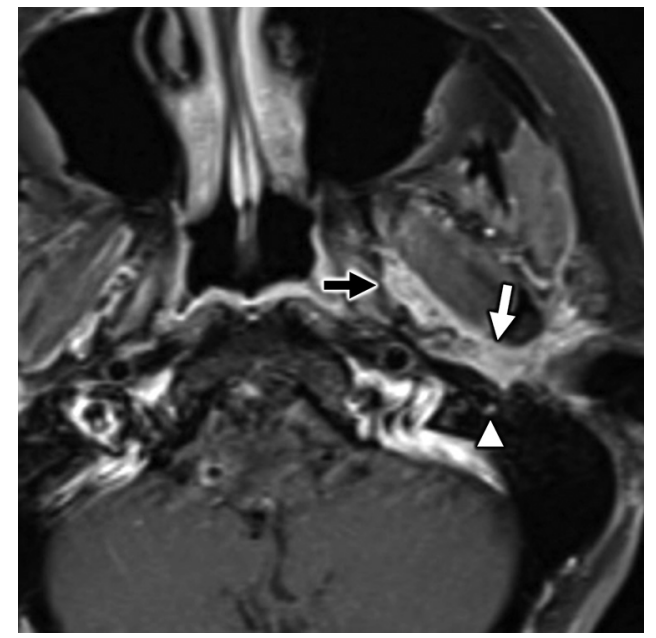

FIG 7. A 35-year-old man with secondary otalgia caused by perineural tumor spread from parotid adenoid cystic carcinoma. Axial T7weighted postcontrast fat-saturated MR imaging shows cordlike enhancement (white arrow) along the course of the auriculotemporal nerve, which serves as an extracranial bridge linking the intraparotid facial nerve to $\mathrm{CN}$ V3 (black arrow) in the infrazygomatic masticator space. Note hyperenhancement along the descending mastoid segment of CN VII (white arrowhead) from additional perineural tumor spread. In this case, referred otalgia may occur along the auriculotemporal nerve, $\mathrm{CN}$ V3, and/or CN VII.

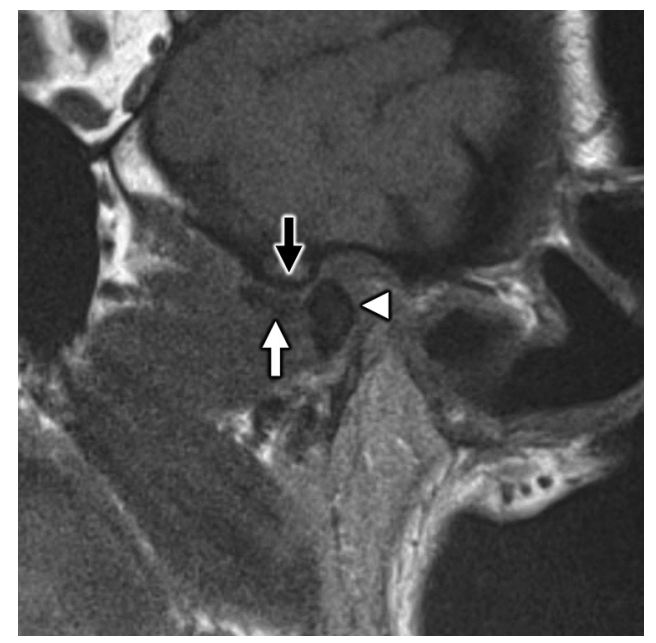

FIG 8. A 58-year-old woman with secondary otalgia caused by TMJ derangement. Oblique sagittal T1-weighted image in open-mouth position demonstrates irregularity and loss of normal biconcave morphology of the articular disk (white arrow), which has been displaced anteriorly. The disk does not recapture upon mouth opening, which prevents normal anterior translation of the mandibular condyle (white arrowhead) with respect to the articular eminence (black arrow). TMJ degeneration is a very common etiology of secondary otalgia with pain likely referred along CN V3.

proximal root entry zone of CN IX (typically by the posterior inferior cerebellar artery or anterior inferior cerebellar artery) may uncommonly manifest glossopharyngeal neuralgia, a rare entity consisting of paroxysmal pain involving the external ear, posterior tongue, and tonsil. ${ }^{47}$

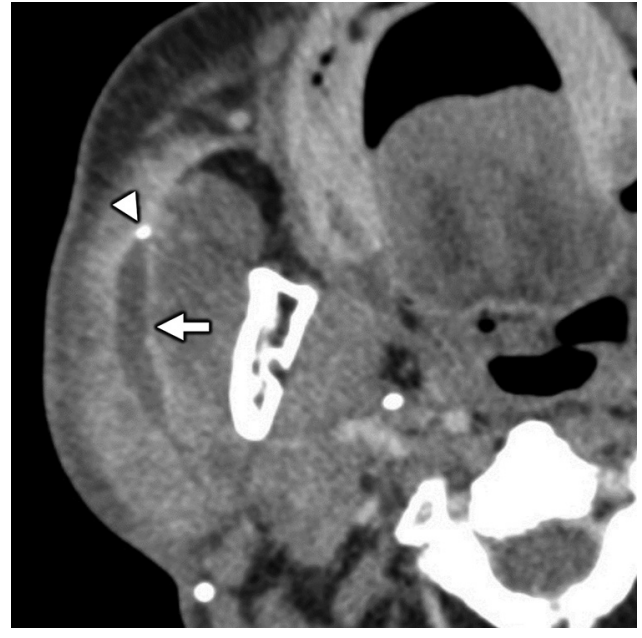

FIG 9. Benign parotid pathology presenting with secondary otalgia. Axial contrast-enhanced CT in a 75-year-old man with right-sided ear pain shows obstructive calculous parotitis and sialodochitis with marked intraparotid ductal dilation (white arrow) and wall enhancement upstream of an obstructing sialolith (white arrowhead). Referred otalgia from intraparotid pathologies is thought to occur via the auriculotemporal nerve, a branch of CN V3.

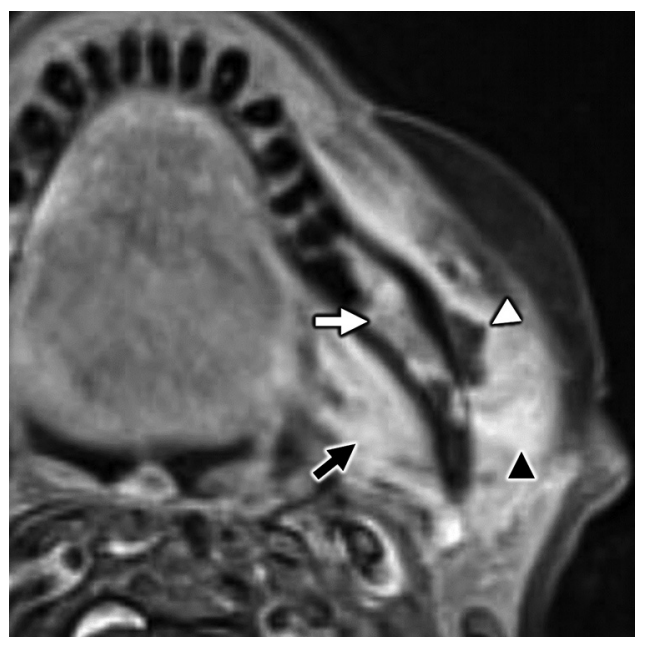

FIG 10. A 42-year-old woman with secondary otalgia due to odontogenic infection. Axial T1-weighted postcontrast fat-saturated MR imaging shows a rim-enhancing subperiosteal abscess (white arrowhead). Note the corresponding hyperenhancing marrow (white arrow) from osteitis and hyperenhancing medial pterygoid (black arrow) and masseter (black arrowhead) muscles from myositis. Odontogenic infection is a common source of referred otalgia via $\mathrm{CN} V 3$ and its branches.

\section{Cranial Nerve $X$}

The vagus nerve $(\mathrm{CN} \mathrm{X})$ is a mixed nerve, transmitting motor, general sensory, special sensory (taste), viscerosensory, and parasympathetic nerve connections to geographically diverse regions of the body, spanning the brain stem, head and neck, chest, and abdomen to the level of the colon. ${ }^{48}$ Similar to CN IX, the vagus nerve is supported by 4 brain stem nuclei that are located in or extend through the medulla, including the nucleus ambiguus 


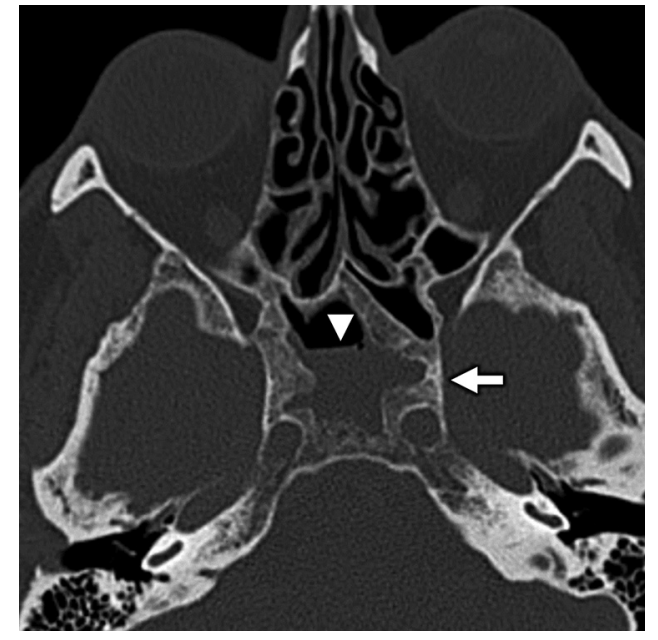

FIG 11. A 64-year-old woman with secondary otalgia caused by sinus mucosal disease. Axial bone algorithm CT shows a partially opacified right sphenoid sinus with marked hyperostosis and sclerosis of the sinus walls from long-standing mucoperiosteal reaction (white arrow) related to sinus mucosal disease. Note an air-fluid level (white arrowhead), which is a nonspecific finding that can be seen in the setting of acute inflammation related to the sinus mucosal disease. Sinus disease is a common source of secondary otalgia, thought to yield referred pain via CN VII parasympathetic branches or via CN V1 sensory branches.

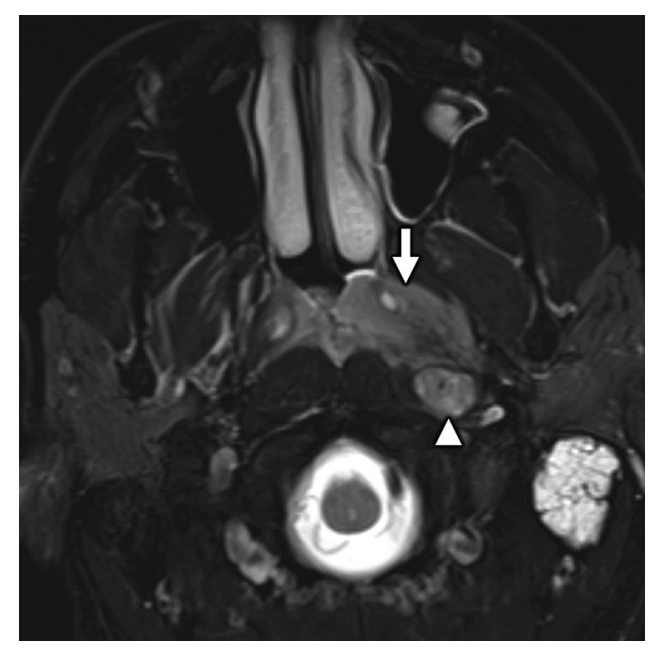

FIG 12. A 52-year-old man with secondary otalgia caused by nasopharyngeal carcinoma (NPC). Axial T2-weighted fat-saturated MR imaging shows an intermediate signal intensity nasopharyngeal mass (white arrow) consistent with a cellular tumor, which extends laterally into the parapharyngeal space. Note the additional metastatic retropharyngeal adenopathy (white arrowhead) and left mastoid effusion. NPC may present with primary and secondary otalgia caused by mastoid-middle ear effusion (primary otalgia) and referred pain along $\mathrm{CN}$ IX (secondary otalgia).

(motor), solitary tract nucleus (taste), dorsal vagal nucleus (viscerosensory afferents and parasympathetic efferents), and spinal nucleus of CN V (general sensory) (Fig 4). CN X departs the medulla laterally at the postolivary sulcus, courses anterolaterally through the basal cistern along with CN IX and CN XI, and travels through the jugular foramen, where it transits the superior

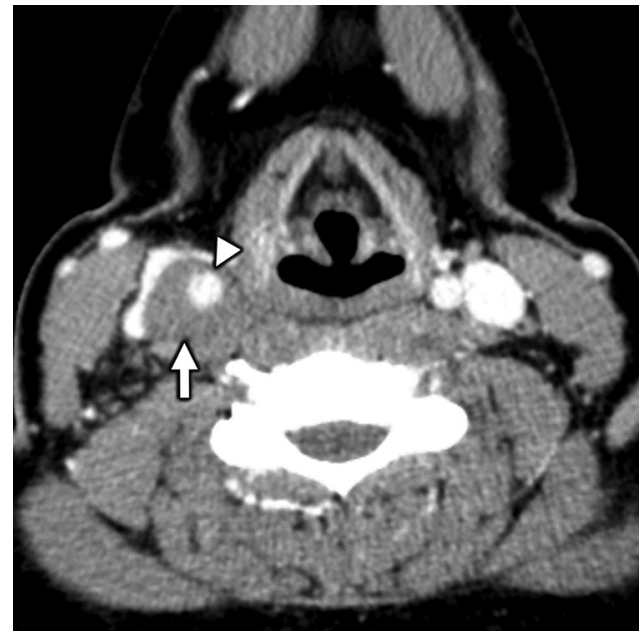

FIG 13. Transient perivascular inflammation of the carotid artery (TIPIC) syndrome presenting as otalgia. Axial contrast-enhanced CT in a 44-year-old woman with TIPIC syndrome shows characteristic segmental, eccentric soft tissue thickening (white arrow) around the wall of the common carotid artery. Note the lack of associated arterial stenosis (white arrowhead). TIPIC syndrome may yield referred otalgia via CN IX and/or CN X branches, depending on which segments of the carotid artery are involved.

vagal ganglion and exits the skull base via the pars vascularis portion of the jugular foramen. Below the skull base, $\mathrm{CN}$ X descends in the carotid space, transiting the nodose ganglion before descending posterolateral to the carotid artery and into the chest.

Primary sensory innervation of the ear via $\mathrm{CN} \mathrm{X}$ is complex and variable but generally includes portions of the concha, postauricular skin, the posterior external auditory canal, and the tympanic membrane via the auricular branch of the vagus nerve (Arnold nerve), which relays from $\mathrm{CN} \mathrm{X}$ via the superior vagal ganglion in the jugular foramen, as well as receives some innervation via CN IX. ${ }^{48}$ The vagus nerve also provides branches to the oropharynx (vallecula), supraglottic larynx (laryngeal and lingual surfaces of the epiglottis), hypopharynx (pyriform sinus), thyroid, cervical esophagus, and trachea via the superior and inferior laryngeal nerves. ${ }^{32}$ This complex $\mathrm{CN} \mathrm{X}$ innervation pathway involving the ear and other geographically remote regions of the body is exemplified by the ear-cough (Arnold nerve) reflex, which can result in the induction of cough as a result of stimulation or manipulation of the external ear. ${ }^{49}$

Many neoplastic causes of referred ear pain can be directly attributed to the $\mathrm{CN} \mathrm{X}$ sensory pathway. Therefore, these structures must be carefully inspected on cross-sectional imaging, particularly if the patient has a history of dysphonia, dysphagia, or dyspnea. ${ }^{50}$ Glottic and supraglottic laryngeal cancer, esophageal carcinoma (Fig 14), and apical lung cancer may all present with otalgia. ${ }^{51-53}$ Benign pathologies, including TIPIC syndrome (Fig 13), thyroiditis, and cricoarytenoid arthropathy, may also cause referred ear pain via CN X afferents. ${ }^{43,54,55}$

\section{APPROACH TO IMAGING}

The approach to imaging referred ear pain should be driven by clinical history and physical examination findings, and it is incumbent on the interpreting radiologist to review the medical record of 
patients evaluated for otalgia. Protocolling of examinations for all permutations of clinical presentations of otalgia is beyond the scope of this review, but in general, the choice of imaging technique and examination is predicated on clinical features, and imaging protocols should be targeted to address specific examination abnormalities. For patients with "red flags," such as weight loss, dysphagia, odynophagia, dyspnea, adenopathy, and advanced age, cross-sectional imaging serves a primary role in screening for occult head and neck malignancy as a potential source of referred ear pain. In

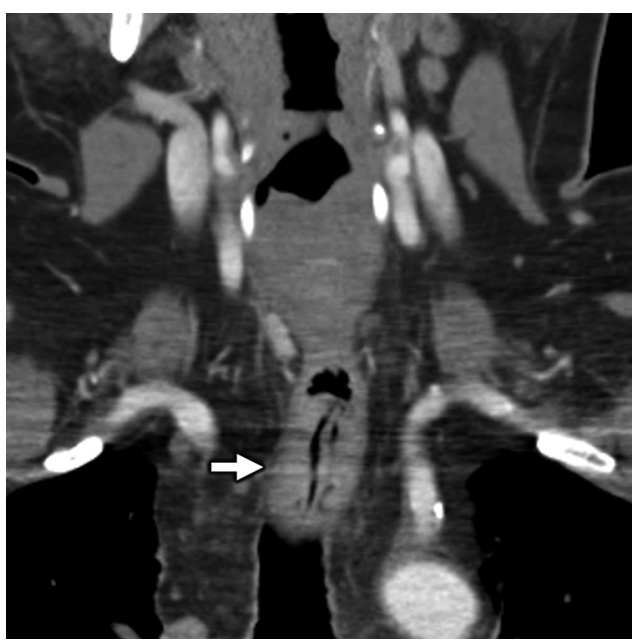

FIG 14. A 58-year-old man with secondary otalgia caused by esophageal carcinoma. Coronal contrast-enhanced CT image shows segmental wall thickening (white arrow) of the distal cervical esophagus corresponding to the esophageal carcinoma. In this case, the referred otalgia likely occurred via CN X branches.

Table 2: Suggested cross-sectional imaging search pattern for secondary otalgia

\begin{tabular}{cl}
\hline \multicolumn{1}{c}{ Component } & \multicolumn{1}{c}{ Specific Sites of Interest } \\
\hline Ear and temporal & External ear \\
bone & External auditory canal \\
& Middle ear, mastoid \\
Inner ear, otic capsule, and petrous apex & Periauricular soft tissues \\
& Midbrain, pons, and medulla \\
Central nervous & Upper cervical spinal cord \\
system & Occipitocervical and atlantoaxial joints \\
Upper cervical nerves & Spinal canal and neural foramina (C II and C III) \\
(C II and C III) & Extracranial course of great auricular and lesser occipital nerves \\
& Cisternal segments \\
CN V, CN VII, CN IX, & Skull base or temporal bone segments \\
and CN X & Extracranial segments (masticator, parotid, and carotid spaces) \\
& Major waystations (pterygopalatine fossa and geniculate \\
& ganglion) \\
"End organs" of & Major salivary glands (parotid, submandibular, and sublingual) \\
innervation & Orbits \\
& Nose and sinonasal cavity \\
& Oral cavity (tongue, mucosa, and palate) \\
& Maxilla and mandible (teeth and TMJ) \\
"Corners" of the & Pharynx (nasopharynx, oropharynx, and hypopharynx) \\
examination & Larynx \\
\hline & Visceral space (thyroid, esophagus, and trachea) \\
& Carotid space (carotid artery and internal jugular vein) \\
& Lymph nodes (cervical, retropharyngeal, and intraparotid) \\
& Imaged portions of the brain \\
Imaged portions of the chest
\end{tabular}

this population, contrast-enhanced CT of the neck is an appropriate first-line imaging technique. For patients with otalgia and symptoms of chronic rhinosinusitis or eustachian tube dysfunction, targeted imaging of the paranasal sinuses with high-resolution CT is a reasonable first-line technique. If ear pain is associated with lower cranial neuropathies, high-resolution CT and MR imaging of the temporal bones are complementary in evaluating for potential skull base causes, such as jugular foramen masses, skull base metastases, and osteomyelitis. In general, contrast-enhanced CT of the soft tissues of the neck is a practical starting point if clinical history and physical examination are noncontributory.

When approaching secondary otalgia on cross-sectional imaging, it is useful to heed the classic head and neck imaging mantra of "image from origin nuclei to end organs" for the search pattern. Under this paradigm, the interpreting radiologist systematically evaluates for central (ie, brain stem or spine) causes and then scans the expected courses of the potentially affected nerves all the way out to their constituent innervation targets for referable pathology. Because multiple upper cervical and lower CNs may be involved, it is imperative to systematically approach the imaging of these complex cases. Regardless of technique, we advocate by using a standard search pattern, which allows the interpreting radiologist to operate in a consistent and strategic manner.

A checklist of our suggested search pattern for secondary otalgia is summarized in Table 2, which is based on a modification of the classic " 10 Ts of referred otalgia" mnemonic. ${ }^{5,56}$ First focus on the ear, evaluating the external, middle, and inner ear structures; surrounding periauricular soft tissues; and overlying skin for pathology. Next, assess for pathology affecting the brain stem and upper cervical cord. Scrutinize the upper cervical (C II and C

III) nerve courses, noting spinal canal and thecal sac stenoses and neural foraminal compromise, as well as scan the expected extraspinal course of the great auricular and lesser occipital nerves. Then, evaluate the course of CN V, CN VII, CN IX, and CN X and their major branches for pathology, starting with the origin nuclei that span the brain stem and upper cervical cord and then assessing their respective cisternal, skull base and temporal bone, and extracranial segments. Special attention is paid to their courses through the masticator, parotid, and carotid spaces, as well as the major $\mathrm{CN}$ waystations (eg, pterygopalatine fossa). Evaluate the major end organs 1 at a time, including the major salivary glands, orbits, nose and paranasal sinuses, oral cavity and tongue, teeth, TMJ, nasopharynx, oropharynx, hypopharynx, larynx, visceral space, and carotid space, making sure to assess for cervical, retropharyngeal, and intraparotid adenopathy. Finally, review imaged portions of the brain and upper chest, 
which can serve as sites of meningeal or visceral referred pain to the ear.

\section{CONCLUSIONS}

Otalgia is common, and when no source is identified on physical examination, a more complete diagnostic work-up is warranted, including medical imaging. Such causes of secondary otalgia may often be identified on cross-sectional imaging (CT and MR imaging), and it is critical for radiologists to be familiar with the complex sensorineural pathways that innervate the ear because referred pain from numerous head and neck sites can manifest as otalgia.

Disclosures: Nicholas Koontz-UNRELATED: Royalties: Amirsys-Elsevier.

\section{REFERENCES}

1. Harrison E, Cronin M. Otalgia. Aust Fam Physician 2016;45:493-97 Medline

2. Olsen KD. The many causes of otalgia. Infection, trauma, cancer. Postgrad Med 1986;80:50-52, 55-56, 61-63 CrossRef Medline

3. Neilan RE, Roland PS. Otalgia. Med Clin North Am 2010;94:961-71 CrossRef Medline

4. Kim SH, Kim TH, Byun JY, et al. Clinical differences in types of otalgia. J Audiol Otol 2015;19:34-38 CrossRef Medline

5. Fenton JE, Uzomefuna V, O'Rourke C, et al. Applying the Ts of referred otalgia to a cohort of 226 patients. Clin Otolaryngol 2018;43:937-40 CrossRef Medline

6. Yanagisawa K, Kveton JF. Referred otalgia. Am J Otolaryngol 1992;13:323-27 CrossRef Medline

7. Shah RK, Blevins NH. Otalgia. Otolaryngol Clin North Am 2003;36:1137-51 CrossRef Medline

8. Chen RC, Khorsandi AS, Shatzkes DR, et al. The radiology of referred otalgia. AJNR Am J Neuroradiol 2009;30:1817-23 CrossRef Medline

9. Osterweis M, Kleinman A, Mechanic D, eds. The anatomy and physiology of pain. In: Pain and Disability: Clinical, Behavioral, and Public Policy Perspectives. National Academies Press; 1987:123-45

10. Hao J, Bonnet C, Amsalem M, et al. Transduction and encoding sensory information by skin mechanoreceptors. Pflugers Arch 2015;467:109-19 CrossRef Medline

11. Bell A. The neurobiology of acute pain. Vet J 2018;237:55-62 CrossRef Medline

12. Marchand $S$. The physiology of pain mechanisms: from the periphery to the brain. Rheum Dis Clin North Am 2008;34:285-309 CrossRef Medline

13. Ralston HJ, 3rd. Pain and the primate thalamus. Prog Brain Res 2005;149:1-10 CrossRef Medline

14. Murray GM. Guest editorial: referred pain. J Appl Oral Sci 2009;17:i

15. Procacci P, Zoppi M, Maresca M, et al. Analgesic action of tetracosactide in chronic pain syndromes. Clin Ter 1981;98:643-46 Medline

16. Pace MC, Passavanti MB, De Nardis L, et al. Nociceptor plasticity: a closer look. J Cell Physiol 2018;233:2824-38 CrossRef Medline

17. Asherson N. Glosso-pharyngeal neuralgia (otalgia) and the elongated styloid process: a record of five cases. J Laryngol Otol 1957;71:453-70 CrossRef Medline

18. Latremoliere A, Woolf CJ. Central sensitization: a generator of pain hypersensitivity by central neural plasticity. J Pain 2009;10:895-926 CrossRef Medline

19. Woolf CJ. Central sensitization: implications for the diagnosis and treatment of pain. Pain 2011;152:S2-15 CrossRef Medline

20. Giamberardino MA. Referred muscle pain/hyperalgesia and central sensitisation. J Rehabil Med 2003;35:85-88 CrossRef Medline

21. Foreman RD, Schmidt RF, Willis WD. Effects of mechanical and chemical stimulation of fine muscle afferents upon primate spinothalamic tract cells. J Physiol (Lond) 1979;286:215-31 CrossRef Medline

22. Milne RJ, Foreman RD, Giesler GJ, Jr, et al. Convergence of cutaneous and pelvic visceral nociceptive inputs onto primate spinothalamic neurons. Pain 1981;11:163-83 CrossRef Medline
23. Lynn RB. Mechanisms of esophageal pain. Am J Med 1992;92:11S19S CrossRef Medline

24. Alvord LS, Farmer BL. Anatomy and orientation of the human external ear. J Am Acad Audiol 1997;8:383-90 Medline

25. Woolf CJ, Salter MW. Neuronal plasticity: increasing the gain in pain. Science 2000;288:1765-69 CrossRef Medline

26. Jaber JJ, Leonetti JP, Lawrason AE, et al. Cervical spine causes for referred otalgia. Otolaryngol Head Neck Surg 2008;138:479-85 CrossRef Medline

27. Danish SF, Zager EL. Cervical spine meningioma presenting as otalgia: case report. Neurosurgery 2005;56:E621 CrossRef Medline

28. Gamrath DJ. Consider atlanto-occipital joint dysfunction as a cause of secondary otalgia. Am Fam Physician 2018;98:142 Medline

29. Holt JJ. Otalgia: the many causes. Wis Dent Assoc J 1987;63:551 Medline

30. Taziki MH, Behnampour N. A study of the etiology of referred otalgia. Iran J Otorhinolaryngol 2012;24:171-76 Medline

31. Vattoth S. CNV (trigeminal nerve). In: Chapman PR, Harnsberger HR, Vattoth S, eds. Imaging Anatomy: Head and Neck. Elsevier; 2019:152-63

32. Scarbrough TJ, Day TA, Williams TE, et al. Referred otalgia in head and neck cancer: a unifying schema. Am J Clin Oncol 2003;26:e15762 CrossRef Medline

33. Schmalfuss IM, Tart RP, Mukherji S, et al. Perineural tumor spread along the auriculotemporal nerve. AJNR Am J Neuroradiol 2002;23:303-11 Medline

34. Bush FM, Harkins SW, Harrington WG. Otalgia and aversive symptoms in temporomandibular disorders. Ann Otol Rhinol Laryngol 1999;108:884-92 CrossRef Medline

35. Erkalp K, Erkalp KN, Ozdemir H. Acute otalgia during sleep (live insect in the ear): a case report. Agri 2009;21:36-38 Medline

36. Kim DS, Cheang P, Dover S, et al. Dental otalgia. J Laryngol Otol 2007;121:1129-34 CrossRef Medline

37. Kim SH. A case of bruxism-induced otalgia. J Audiol Otol 2016;20:123-26 CrossRef Medline

38. Chapman PR, Harnsberger HR. CNVII (facial nerve). In: Chapman PR, Harnsberger HR, Vattoth S, eds. Imaging Anatomy: Head and Neck. Elsevier; 2019:168-75

39. Charlett SD, Coatesworth AP. Referred otalgia: a structured approach to diagnosis and treatment. Int J Clin Pract 2007;61:1015-21 CrossRef Medline

40. Nanda MS, Kaur M, Bhatia S. Impact of septoplasty on hearing and middle ear function. Int J Res Med Sci 2018;6:135-39 CrossRef Medline

41. Singhal A, Harnsberger HR. CNIX (glossopharyngeal nerve). In: Chapman PR, Harnsberger HR, Vattoth S, eds. Imaging Anatomy: Head and Neck. Elsevier; 2019;182-87

42. Grosskopf CC, Kuperstein AS, O’Malley BW Jr, et al. Parapharyngeal space tumors: another consideration for otalgia and temporomandibular disorders. Head Neck 2013;35:E153-56 CrossRef Medline

43. Hill LM, Hastings G. Carotidynia: a pain syndrome. J Fam Pract 1994;39:71-75 Medline

44. Kim KS. Referred otalgia induced by a large tonsillolith. Korean J Fam Med 2013;34:221-23 CrossRef Medline

45. Naraev BG, Linthicum FH, Jr. Traumatic neuroma of the tympanic (Jacobson's) nerve as a possible cause of otalgia. Otolaryngol Head Neck Surg 2008;138:735-37 CrossRef Medline

46. Lecler A, Obadia M, Savatovsky J, et al. TIPIC syndrome: beyond the myth of carotidynia, a new distinct unclassified entity. AJNR Am J Neuroradiol 2017;38:1391-98 CrossRef Medline

47. Haller S, Etienne L, Kovari E, et al. Imaging of neurovascular compression syndromes: trigeminal neuralgia, hemifacial spasm, vestibular paroxysmia, and glossopharyngeal neuralgia. AJNR Am J Neuroradiol 2016;37:1384-92 CrossRef Medline

48. Singhal A, Harnsberger HR. CNX (vagus nerve). In: Chapman PR, Harnsberger HR, Vattoth S, eds. Imaging Anatomy: Head and Neck. Elsevier; 2019:188-93

49. Dicpinigaitis PV, Kantar A, Enilari O, et al. Prevalence of Arnold nerve reflex in adults and children with chronic cough. Chest 2018;153:67579 CrossRef Medline 
50. Thaller SR, De Silva A. Otalgia with a normal ear. Am Fam Physician 1987;36:129-36 Medline

51. Kellerhals B. Pain syndromes of the head, neck and locomotor system-determining current status. HNO 1984;32:181-89 Medline

52. Kuo YW, Chen KY, Chang YL, et al. Small-cell lung carcinoma presenting with otalgia and hearing impairment. J Clin Oncol 2008;26:4690-92 CrossRef Medline
53. Rareshide EH, Amedee RG. Referred otalgia. J La State Med Soc 1990;142:7-10 Medline

54. Jajić I, Dubravica M, Jajić Z. Rheumatoid arthritis in the cricoarytenoid joint. Reumatizam 1994;41:13-14 Medline

55. Stevenson J. Acute bacterial thyroiditis presenting as otalgia. $J$ Laryngol Otol 1991;105:788-89 CrossRef Medline

56. Harvey H. Diagnosing referred otalgia: the ten Ts. Cranio 1992;10:333-34 CrossRef Medline 
n the article "Secondary Otalgia: Referred Pain Pathways and Pathologies" by Norris CD and Koontz NA (AJNR Am J Neuroradiol

2020;41:2188-98), cervical nerves 2 and 3 were incorrectly printed as cranial nerves II and III.

The journal regrets the error.

http://dx.doi.org/10.3174/ajnr.A7035 